\title{
LEVANTAMENTO DA ARBORIZAÇÃO DO CANTEIRO CENTRAL DA AVENIDA BRASIL (BAIRRO CENTRO) NO MUNICÍPIO DE PASSO FUNDO, RS
}

\author{
SURVEY OF THE MEDIAN STRIP AFFORESTATION OF BRASIL AVENUE \\ (NEIGHBORHOOD CENTER) IN THE MUNICIPALITY OF PASSO FUNDO, RS
}

Jackson Vinícius Rodrigues Pereira' ${ }^{1}$, Leonita Beatriz Girardi², Janine Farias Menegaes ${ }^{3}$, Ítalo Girardi Ferreira ${ }^{4}$, Daniela Machado Monteiro ${ }^{5}$

\section{RESUMO}

A arborização urbana é de suma importância para o bem estar da população, bem como na composição da paisagem arquitetônica do município. Neste sentido, o presente trabalho teve como objetivo elaborar um inventário da arborização do canteiro central da Avenida Brasil I do bairro Centro, no município de Passo Fundo, RS, identificando as espécies e suas condições sanitárias e físicas. Assim, realizou-se o levantamento da arborização, no período de agosto a outubro de 2019, por meio de um inventário qualiquantitativo da totalidade da vegetação arbórea presente no canteiro central da Avenida Brasil no bairro Centro em Passo Fundo, RS. A partir dos dados obtidos, observou-se que o trecho da avenida inventariado apresenta 427 espécies arbóreas distribuidas em 32 famílias botânicas, sendo $56,3 \%$ de origem exótica, em que $49,18 \%$ deste total correspondem apenas a duas espécies arbóreas, o ligustro (Ligustrum lucidum) e a tipuana (Tipuana tipu). Conclui-se que apesar do alto número de indivíduos arbóreos, nem todos são indicados para a arborização urbana, sendo necessário um replanejamento para esse trecho da avenida, recomendando-se a substitução dessas espécies classificadas como inadequadas ou em péssimo estado de conservação.

Palavras-chave: Diagnóstico das árvores; Paisagismo urbano; Planejamento florístico.

\begin{abstract}
Urban afforestation is of paramount importance for the well-being of the population, as well as in the composition of the municipality's architectural landscape. In this sense, the present study had as objective to elaborate an inventory of the afforestation of the median strip of Brazil Avenue in the Centro district, in the municipality of Passo Fundo, RS, identifying the species and their sanitary and physical conditions. Thus, the survey of afforestation was carried out, from August to October 2019, through a qualitative and quantitative inventory of the totality of tree vegetation present in the median strip of Brazil Avenue in the Centro district in Passo Fundo, RS. From the data obtained, it was observed that the stretch of the inventoried avenue has 427 tree species distributed in 32 botanical families, $56.3 \%$ of which are of exotic origin, with $49.18 \%$ of this total corresponding only to two tree species, the privet (Ligustrum lucidum) and tipuana (Tipuana tipu). It is concluded that, despite the high number of tree individuals, not all are indicated for urban afforestation, being necessary a re-planning for this stretch of the avenue, it is recommended to replace these species classified as inadequate or in a poor state of conservation.
\end{abstract}

Keywords: Diagnosis of trees; Urban landscaping; Floristic planning.

Recebido em 19.05.2020 e aceito em 03.12.2020

1 Engenheiro Agrônomo. Instituto de Desenvolvimento Educacional de Passo Fundo (UNIDEAU). Passo Fundo/RS. E-mail: jacksonvrp@hotmail.com

2 Agrônoma. Docente na Faculdade UNIDEAU. Passo Fundo/RS. E-mail: Ibgirardi@hotmail.com

3 Engenheira Agrônoma. Drª. Universidade Federal de Santa Maria. Santa Maria/RS. E-mail: janine_rs@hotmail.com

4 Acadêmico de Agronomia. Universidade de Passo Fundo (UPF). Passo Fundo/RS. E-mail: italogf@icloud.com

5 Acadêmica de Agronomia. Instituto de Desenvolvimento Educacional de Passo Fundo (UNIDEAU). Passo Fundo/RS. E-mail: machadodaniela63@live.com 


\section{INTRODUÇÃO}

Um projeto de arborização adequado deve atender aos valores culturais, ambientais e de memória do municipio em que é implantado. Além de levar em consideração sua ação potencial de proporcionar conforto para a população, sombreamento, abrigo e alimento para avifauna, diversidade biológica, redução dos índices de poluição, proporcionar melhoras de condições de permeabilidade do solo e paisagem, possibilitando contribuições ajustadas com a melhoria das condições urbanísticas e arquitetônicas (BIONDI; PEDROSA-MACEDO, 2008; RESENDE, 2011).

A presença de vegetação em ambientes urbanos desempenha diversos serviços ecossistêmicos que trazem benefícios ecológicos. Entre eles os canteiros centrais podem formar elos entre as demais áreas verdes e ruas arborizadas, formando corredores e criando oportunidades para o enriquecimento da biodiversidade. A vegetação promove a melhoria microclimática, acústica, da qualidade do ar e da drenagem das águas pluviais; a proteção do solo contra erosão e a sobrevivência da fauna; sendo que as árvores, no geral, são essenciais para o bem-estar da população humana (ROBBA; MACEDO, 2010; MARTINI; BIONDI, 2015; VIEZZER et al., 2018; FALCÃO et al., 2020).

Muitas vezes as avenidas são lembradas devido à sua arborização, comumente as pessoas referem à determinada rua como "aquela que tem árvores bem altas", por exemplo. Ou seja, torna-se uma característica do lugar, faz parte da estrutura urbana (CABRAL, 2013). Todavia, há grande preocupação com a diversidade de espécies nos municípios, por ser um dos atributos de qualificação da sustentabilidade da arborização urbana e por visar à redução das perdas ocasionadas por pragas e doenças, bem como o prolongamento dos benefícios proporcionados pelas árvores (KENNEY et al., 2011; TEIXEIRA et al., 2011; SILVA et al., 2017).

Em muitos municípios, a arborização se inicia pela avenida principal, em Passo Fundo, RS, esse processo ocorreu na Avenida Brasil. Via aberta junto a fundação do município em 1733, atualmente, sua extensão é de aproximadamente $10 \mathrm{~km}$ de leste a oeste. Essa avenida é de grande importância no fluxo econômico-político-viário em virtude aos acessos às regiões próximas, a qual interligam duas rodovias: a federal (BR-153) e a estadual (RS-285), que possibilitam conexões importantes com os demais Estados Brasileiros, bem como os países do MERCOSUL (Mercado Comum do Sul) (NECKEL et al., 2014; IBGE, 2019).

O município de Passo Fundo fazia parte da Rota dos Tropeiros, por meio da Estrada das Missões, na qual a Avenida Brasil, conhecida na época como Rua do Comércio com grande importância socioeconômica, interligava a Região Norte do Estado aos demais municípios e países sulinos. Ainda, sobre a memória cultural, a Avenida Brasil teve seu processo de arborização entre as décadas de 1960 - 1970, com espécies como ligustro (Ligustrum lucidum 
W. T. Aiton), que apresentavam boa adaptabilidade a região, sendo disseminada em vários municípios gaúchos nessa época. Na sequência utilizaram outras espécies, por exemplo, canafístulas (Peltophorum dubium (Spreng.) Taub.), ipês-rosa (Handroanthus avellanedae (Lor. ex Griseb.) Mattos), jacarandás (Jacaranda mimosifolia D. Don) e tipuanas (Tipuana tipu (Benth.) Kuntze) (MELO; SEVERO, 2010).

Importante destacar que em 2019, a Avenida Brasil passou por revitalização, tanto das calçadas para pedestres como da rede de esgoto e da vegetação. Em relação a vegetação, o canteiro central está sendo enleivado e mudas de árvores estão sendo introduzidas, assim como substituição de exemplares em franca senescência. As obras da Avenida Brasil estão divididas em três projetos: o primeiro abrange pavimentação, ciclovia, drenagem, acessibilidade e sinalização; o segundo compreende ampliação e substituição da rede de esgoto; e o terceiro inclui melhorias na rede de infraestrutura elétrica (PASSO FUNDO, 2019).

Neste sentido, o presente trabalho teve como objetivo elaborar um inventário da arborização do canteiro central da Avenida Brasil no bairro Centro, no município de Passo Fundo, RS, identificando as espécies e suas condições sanitárias e físicas.

\section{MATERIAL E MÉTODOS}

O levantamento da arborização foi realizado por meio de um inventário quali-quantitativo da totalidade da vegetação arbórea presente no canteiro central da Avenida Brasil no bairro

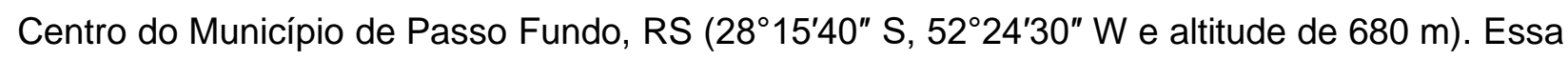
avenida é a principal da região central do município e sua extensão contempla três bairros (Boqueirão, Centro e Petrópolis), sendo que neste trabalho avaliou-se o inventário arbóreo do Bairro Centro (Figura 1). O trecho inventário contempla a extensão de 2.516,75 m, sendo que a largura do canteiro central onde foi feito o levantamento varia entre 7,86 e 1,28 m, em função da estrutura urbana. O período do levantamento foi de agosto a outubro de 2019.

O município de Passo Fundo, RS, possui aproximadamente 203.275 habitantes, com área próxima de 783,4 km², localizado na região Norte está distante $289 \mathrm{~km}$ da capital Porto Alegre. Apresenta Índice de Desenvolvimento Humano $\left(\mathrm{IDH}^{2} ; 2010\right)$ de 0,776 e Índice de Desenvolvimento Socioeconômico (IDESE3; 2016) de 0,789 (IBGE, 2019; SEBRAE, 2019). O clima na região é subtropical úmido (Cfa), segundo a classificação de Köppen-Geiger, com

\footnotetext{
${ }^{2}$ IDH do Brasil foi de 0,759 e do Rio Grande do Sul (RS) foi de 0,746 (IBGE Cidades@, 2019; SEBRAE PERFIL CIDADES GAÚCHAS, 2019).

${ }^{3}$ O IDESE avalia a situação socioeconômica dos municípios gaúchos quanto à educação, à renda e à saúde, considerando aspectos quantitativos e qualitativos do processo de desenvolvimento. O RS atingiu a marca de 0,751 em 2016 (SEBRAE PERFIL CIDADES GAÚCHAS, 2019).
} 
amplitude entre $12,7^{\circ} \mathrm{C}$ no inverno e $22,9^{\circ} \mathrm{C}$ no verão, e umidade relativa do ar (média anual) de $72 \%$.

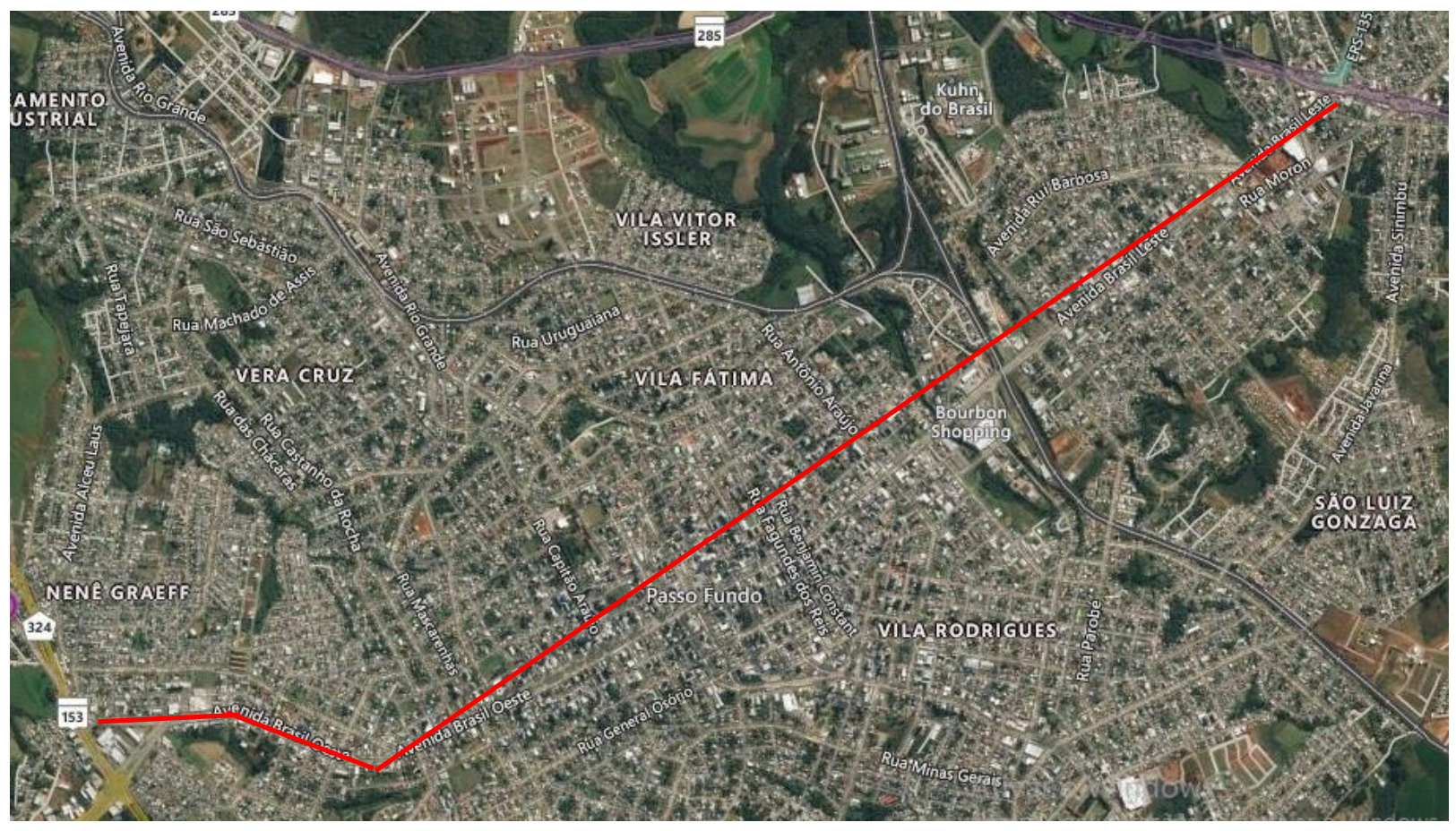

Fonte: adaptado do Google Earth (2020).

Figura 1. Imagem da Avenida Brasil do município de Passo Fundo, RS (traçado em vermelho).

Figure 1. Image of Brazil Avenue in the municipality of Passo Fundo, RS (outlined in red).

As espécies vegetais foram classificadas quanto:

a) Classes de altura e de diâmetro de copa:
1) $<1 \mathrm{~m}$;
2) $1,1-4 \mathrm{~m}$;
3) 4,1-8 m;
4) $8,1-12 \mathrm{~m}$;
5) 12,1-16 m;
6) $16,1-20 \mathrm{~m}$;
7) $>20 \mathrm{~m}$.

b) Estado geral dos indivíduos avaliados adaptado de Silva Filho et al. (2002): Ótimo: indivíduo plenamente vigoroso e sadio, sem sinais de ataque de pragas, doenças ou injúrias mecânicas, mantendo suas características arquitetônicas; Bom: indivíduo com boas condições gerais de vigor e sanidade, podendo apresentar algum sinal de deficiência superficial, ataque de pragas ou doenças, ou injúria mecânica superficial, porém em bom estado; Regular: indivíduo em início de declínio, podendo apresentar ataque severo de pragas, doenças, injúrias mecânicas ou presença de parasitas, descaracterizando sua arquitetura, desequilibrando o vegetal ou ainda apresentando deficiência; Péssimo: indivíduo em estado avançado e irreversível de declínio, com ataque ou dano intenso de pragas, doenças, deficiências ou presença de parasitas prejudicando a função do indivíduo na arborização e causando risco de queda ou morte do vegetal; Morta: indivíduo morto ou em estado de morte iminente, perdendo a função na arborização. 
c) Frquência relativa de cada espécie: calculada pela razão entre o número de indivíduos da espécie e o número total de indivíduos dentro de cada grupo (arbóreas, palmeiras, arbustos e trepadeira), multiplicada por 100.

d) Índice de riqueza de espécies: calculado segundo Silva Filho et al. (2002), pela equação [ $\left.d=(S-1) / \log _{10} N\right]$, em que: $d$ = riqueza de espécies; $S$ = número de espécies; $N$ = número total de indivíduos.

Para a identificação das espécies botânicas coletadas foi utilizada literatura especializada (LORENZI; SOUZA, 2008; LORENZI, 2015).

\section{RESULTADOS E DISCUSSÃO}

As espécies arbóreas totalizaram 427 indivíduos distribuídas em 32 distintas famílias botânicas (Tabela 1), sendo 56,3\% e 43,7\% destas de origem exótica e nativa, respectivamente. Verificou-se que a parte avaliada da Avenida Brasil apresenta na sua totalidade espécies arbóreas em estágio adulto, pois o início do processo de arborização se deu entre as décadas de 1960 - 1970. Neste período o uso de espécies de origem exótica era muito mais valorizado, inclusive pelo processo sócio-político-econômico próprio da época.

Viezzer et al. (2018) observaram no seu levantamento paisagístico das Praças de Curitiba, PR, que 56,7\% da vegetação era de origem exótica, sendo também influenciado pelo desenvolvimento da época de execução dos projetos, nas décadas de 1970. Schwab et al. (2014) verificando a diversidade florística do Bairro Nossa Senhora das Dores em Santa Maria, RS observaram índice de $69,3 \%$ da vegetação sendo classificada como exótica. Segundo Dias e Costa (2008), a importância das espécies vegetais nativas no ecossistema, propicia o equilíbrio ecológico entre a flora e fauna, além valorizar a identidade vegetal local.

Entre as 427 espécies presentes na Avenida Brasil no trecho do bairro Centro, 49,18\% das espécies corresponde à duas arbóreas de origem exótica: o ligustro (Ligustrum lucidum) (Figura 2) e a tipuana ( Tipuana tipu), conforme apresentado na Tabela 1.

Para o trecho inventariado da avenida em 2.516,75 m, há uma grande diversidade botânica com 32 famílias (427 indivíduos), obtendo o índice de riqueza de espécies de 11,79. Isto indica de em média a cada 5,9 m deste trecho há uma espécie arbórea, obtendo um bom índice de espécies no trecho estudado. Esse resultado vai de encontro aos verificados por Andreatta et al. (2011) para a arborização das principais avenidas do bairro Centro de Santa Maria, RS, onde encontraram 95 espécies com índice de riqueza de 12,03, considerado pelos autores como bom. 
Tabela 1. Identificação, origem nativa (N) ou exótica (E), família, número de exemplares (№) e frequência relativa (FR) das espécies arbóreas presentes na Avenida Brasil, bairro Centro em Passo Fundo, RS, 2019.

Table 1. Identification, native $(\mathrm{N})$ or exotic $(\mathrm{E})$ origin, family, number of specimens (No.) and relative frequency $(\mathrm{FR})$ of the tree species present on Brazil Avenue, Centro neighborhood in Passo Fundo, RS, 2019.

\begin{tabular}{|c|c|c|c|c|c|}
\hline Espécie & Nome científico & Família & Origem & №. & FR\% \\
\hline Ligustro & Ligustrum lucidum W. T. Aiton & Oleaceae & $\mathrm{E}$ & 162 & 37,94 \\
\hline Tipuana & Tipuana tipu (Benth.) Kuntze & Fabaceae & $\mathrm{E}$ & 48 & 11,24 \\
\hline Ipê-rosa & $\begin{array}{c}\text { Handroanthus avellanedae (Lor. ex Griseb.) } \\
\text { Mattos }\end{array}$ & Bignoniaceae & $\mathrm{N}$ & 37 & 8,67 \\
\hline Timbaúva & Enterolobium contortisiliquum (Vell.) Morong & Fabaceae & $\mathrm{N}$ & 26 & 6,09 \\
\hline Ipê-roxo & Handroanthus heptaphyllus (Vell.) Mattos & Bignoniaceae & $\mathrm{N}$ & 23 & 5,39 \\
\hline Canafístula & Peltophorum dubium (Spreng.) Taub. & Fabaceae & $\mathrm{N}$ & 23 & 5,39 \\
\hline Uva-do-Japão & Hovenia dulcis Thunb. & Rhamnaceae & $\mathrm{E}$ & 23 & 5,39 \\
\hline Juniperus & Juniperus communis L. & Cupressaceae & $E$ & 16 & 3,75 \\
\hline Ipê-amarelo & $\begin{array}{c}\text { Handroanthus chrysotrichus (Mart. Ex A.DC.) } \\
\text { Mattos }\end{array}$ & Bignoniaceae & $\mathrm{N}$ & 12 & 2,81 \\
\hline Jerivá & Syagrus romanzoffiana (Cham.) Glassm. & Arecaceae & $\mathrm{N}$ & 6 & 1,41 \\
\hline Sibipiruna & Caesalpinia peltophoroides (Benth.) G. P. Lewis & Caesalpinoideae & $\mathrm{N}$ & 6 & 1,41 \\
\hline Extremosa & Lagerstroemia indica (L.) Pers. & Lythraceae & $\mathrm{E}$ & 6 & 1,41 \\
\hline Jacarandá Mimoso & Jacaranda mimosifolia D. Don & Bignoniaceae & $\mathrm{E}$ & 5 & 1,17 \\
\hline Embaúba & Cecropia pachystachya Trécul. & Urticaceae & $\mathrm{N}$ & 5 & 1,17 \\
\hline Araucária & Araucaria angustifolia (Bertol.) Kuntze & Araucariaceae & $\mathrm{N}$ & 3 & 0,70 \\
\hline Ingá & Inga edulis Martius & Fabaceae & $\mathrm{N}$ & 3 & 0,70 \\
\hline Dedaleiro & Lafoensia pacari Pohl. & Lythraceae & $\mathrm{N}$ & 3 & 0,70 \\
\hline Jambolão & Syzygium cumini (L.) Skeels & Myrtaceae & $\mathrm{E}$ & 3 & 0,70 \\
\hline $\begin{array}{l}\text { Tamareira-das- } \\
\text { Canárias }\end{array}$ & Phoenix canariensis Hort. ex Chabaud & Arecaceae & $\mathrm{E}$ & 2 & 0,47 \\
\hline Canela & Cinnamomum verum J. Presl. & Lauraceae & $\mathrm{E}$ & 2 & 0,47 \\
\hline Cinamomo & Melia azedarach L. & Meliaceae & $E$ & 2 & 0,47 \\
\hline Palmeira Buriti & Mauritia flexuosa L. & Arecaceae & $\mathrm{E}$ & 1 & 0,23 \\
\hline Cipreste-Português & Cupressus Iusitânica Mill. & Cupressaceae & $\mathrm{E}$ & 1 & 0,23 \\
\hline Cássia & Cassia spectabilis (L.) D C. & Fabaceae & $\mathrm{N}$ & 1 & 0,23 \\
\hline Abacateiro & Persea americana Nill. & Lauraceae & $\mathrm{E}$ & 1 & 0,23 \\
\hline Cedro & Cedrela fissilis Vell. & Meliaceae & $\mathrm{N}$ & 1 & 0,23 \\
\hline Ficus & Ficus benjamina L. & Moraceae & $\mathrm{E}$ & 1 & 0,23 \\
\hline Figueira & Ficus carica L. & Moraceae & $\mathrm{E}$ & 1 & 0,23 \\
\hline Cereja Nativa & Eugenia involucrata D C. & Myrtaceae & $\mathrm{N}$ & 1 & 0,23 \\
\hline Pitangueira & Eugenia uniflora L. & Myrtaceae & $\mathrm{N}$ & 1 & 0,23 \\
\hline Pinus & Pinus taeda L. & Pinaceae & $E$ & 1 & 0,23 \\
\hline Ameixa-amarela & Eriobotrya japonica (Thunb.) Lindl. & Rosaceae & $\mathrm{E}$ & 1 & 0,23 \\
\hline \multicolumn{4}{|c|}{ Total de espécies } & 427 & $100 \%$ \\
\hline
\end{tabular}

Santos et al. (2015) lista algumas espécies as quais não são indicadas para a arborização urbana, por causar algum tipo de dano ao calçamento ou alergia a população, bem como espécies arbóreas com frutos de médio a grande porte, por exemplo, o abacateiro (Persea americana Nill.). Na Tabela 1, espécies tais como uva-do-Japão (Hovenia dulcis Thunb.), cinamomo (Melia azedarach L.) e pinus (Pinus taeda L.), se enquadram na lista de espécies inadequadas para a arborização urbana preconizada por Santos et al. (2015). Recomenda-se a substituição dessas espécies assim que possível. 


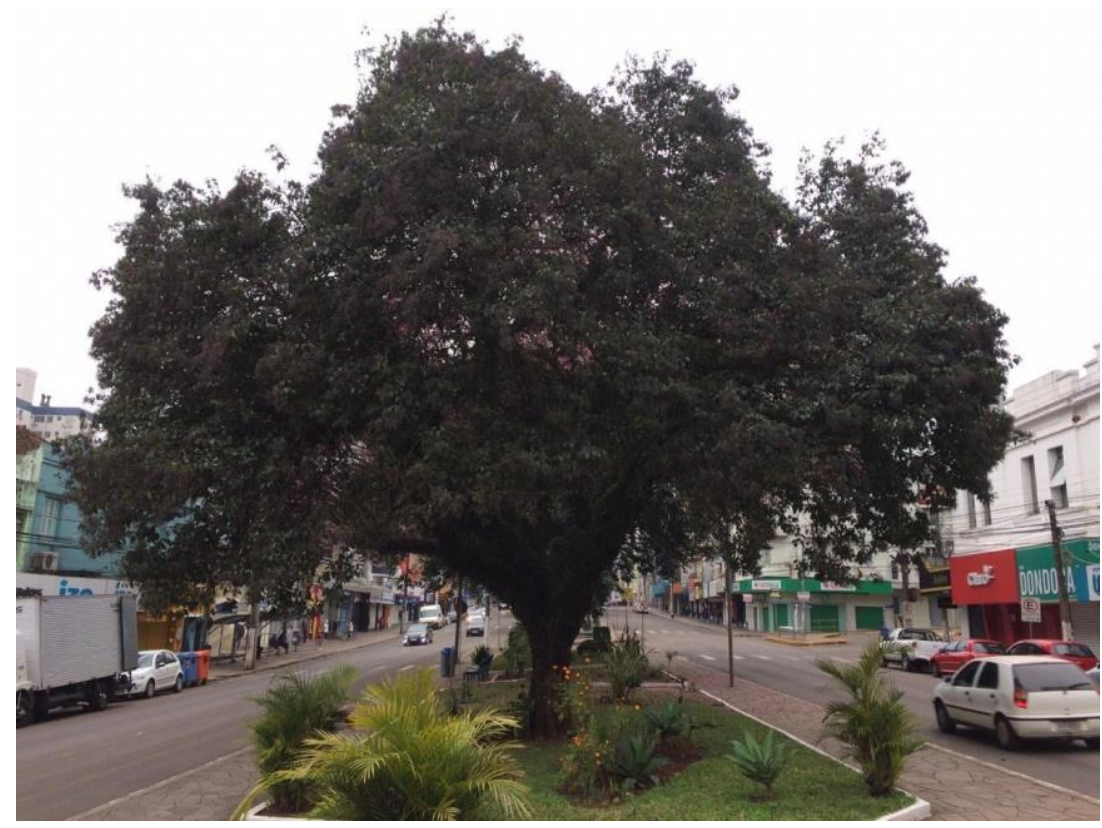

Figura 2. Um exemplar de Ligustro (Ligustrum lucidum) localizado no canteiro com outras espécies de folhagem plantas ao redor na Avenida Brasil, Passo Fundo, RS. Foto: Autores (2019).

Figure 2. A specimen of Ligustro (Ligustrum lucidum) located in the median strip with other species of foliage plants around on Brazil Avenue, Passo Fundo, RS. Photo: Authors (2019).

Na Figura 3, entre as 32 famílias botânicas, destaca-se a família Fabaceae com cinco espécies vegetais, tipuana ( $T$. tipu), timbaúva ( $E$. contortisiliquum), canafístula ( $P$. dubium), ingá (I. edulis) e cássia (C. spectabilis), assim com contribuição de $23,65 \%$ da vegetação total do trecho estudado. Na sequência a família Bignoniaceae apresenta 12,5\% com 4 espécies em destaque os ipês $(H$. avellanedae, $H$. heptaphyllus e $H$. chrysotrichus) e os jacarandás (J. Mimosifolia). E, as familias Arecaceae (palmeiras) e Myrtaceae (frutíferas) ambas com 9,4\% cada do total de espécies (Tabela 1). De acordo com Viezzer et al. (2018) nas Praças de Curitiba, PR as famílias botânicas de maior ocorrência são as Fabaceae $(16,3 \%)$, Arecaceae $(5,7 \%)$ e Myrtaceae (5,0\%). Para Lorenzi e Souza (2008), no Brasil a família Fabaceae é a mais utilizada na arborização urbana, devido ao seu porte e frondosidade. 


\section{Famílias Botânicas}

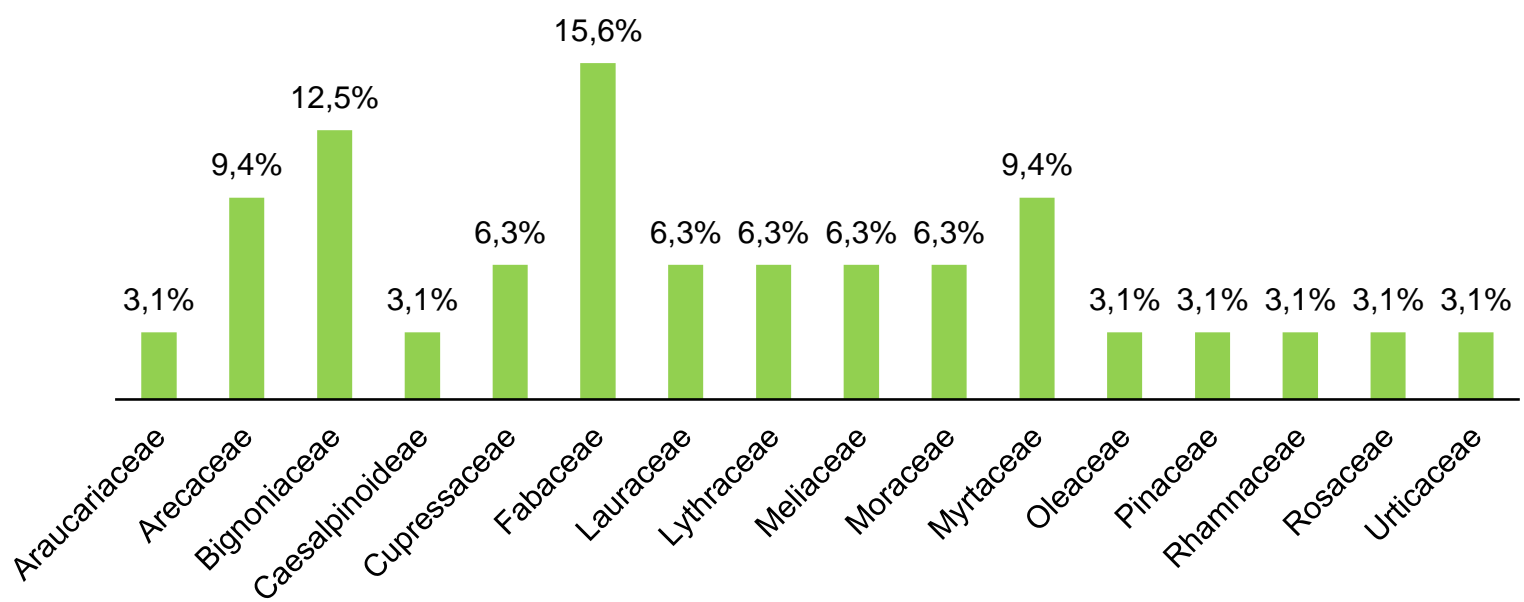

Figura 3. Distribuição percentual das famílias botânicas das espécies presentes na Avenida Brasil, bairro Centro em Passo Fundo, RS, 2019.

Figure 3. Percentage distribution of the botanical families of the species present on Brazil Avenue, Centro neighborhood in Passo Fundo, RS, 2019.

Verificou-se, a partir das características gerais das espécies presentes na Avenida Brasil no trecho do bairro Centro, que o estado das arbóreas é de boa conservação, sendo 51,4\% considerado em bom estado e 10,3\% em ótimo estado de conservação (Figura 4a). Para as espécies classificadas em péssimas condições $(8,4 \%)$ recomenda-se a substituição desses exemplares, visando adequar a sanidade da vegetação da Avenida Brasil. Resultados semelhantes aos deste trabalho foram verificados por Schwab et al. (2014) com a vegetação próxima de 50\% em bom estado para o Bairro Nossa Senhora das Dores em Santa Maria, RS.

Observou-se que nas Figuras $4 b$ e 4c, tanto para a altura média como para o diâmetro médio das espécies a maior parte das árvores apresentam valores acima de $20 \mathrm{~m}$, isto indica que estas encontram-se em estágio adulto, e que as espécies escolhidas apresentam grande porte.

Apesar de algumas espécies serem inapropriadas para a arborização urbana, devido ao seu porte, diâmetro de copa, sistema radicular, entre outros, no trecho da Avenida Brasil tem-se 427 espécies arbóreas, isto proporciona a esta área urbana um ambiente altamente arborizado formando um corredor verde. De acordo com Santos et al. (2015) corredores verdes proporcionam a população um contato mais íntimo com meio ambiente em que estão inseridos. Uma vez que, a arborização urbana presente em um município torna-se um bem ambiental. E, como tal, deve ser valorado, de acordo com Menegaes et al. (2014), a valoração ambiental, atua como um contrato social de bem viver entre o homem e o ambiente, confirmando seu direito previsto no Artigo no. 225 da Constituição da República Federativa do Brasil (1988), o qual dispõe que "todos têm direito ao meio ambiente ecologicamente equilibrado, bem de uso comum do 
povo e essencial à sadia qualidade de vida, impondo-se ao Poder Público e à coletividade o dever de defendê-lo e preservá-lo para o presente e futuras gerações".

a)

Estado geral das espécies

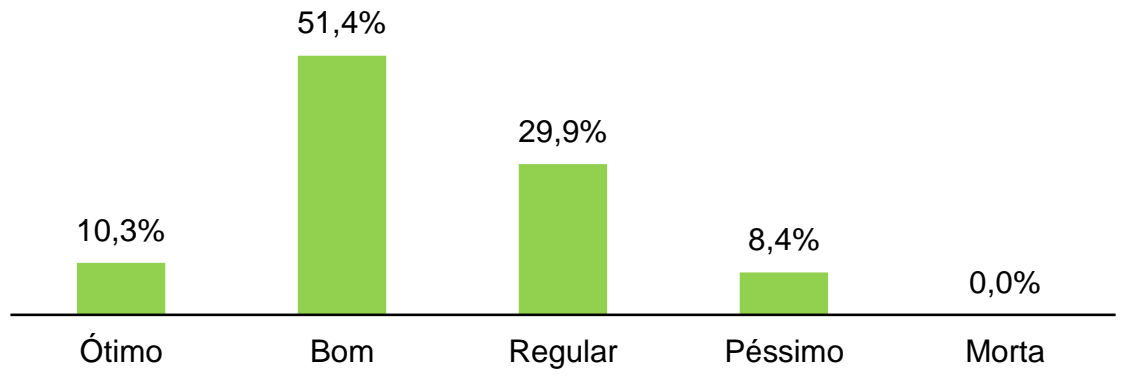

b)

Altura média das espécies $(\mathrm{m})$

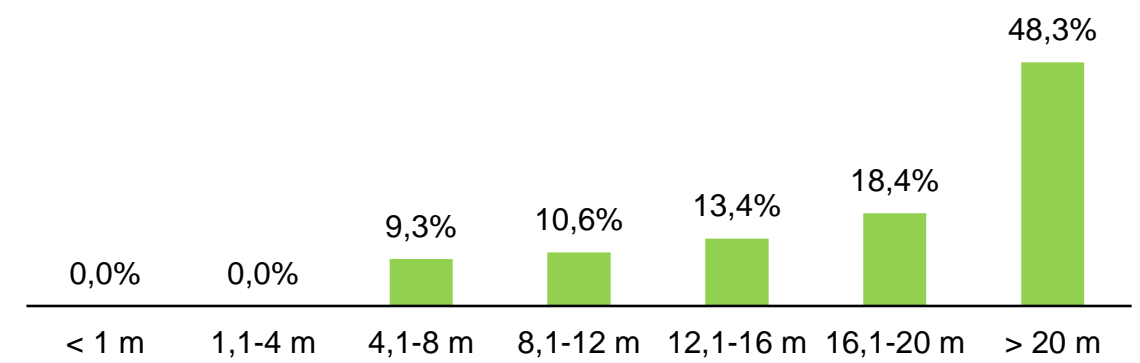

c) Diâmetro médio da copa das espécies (m)

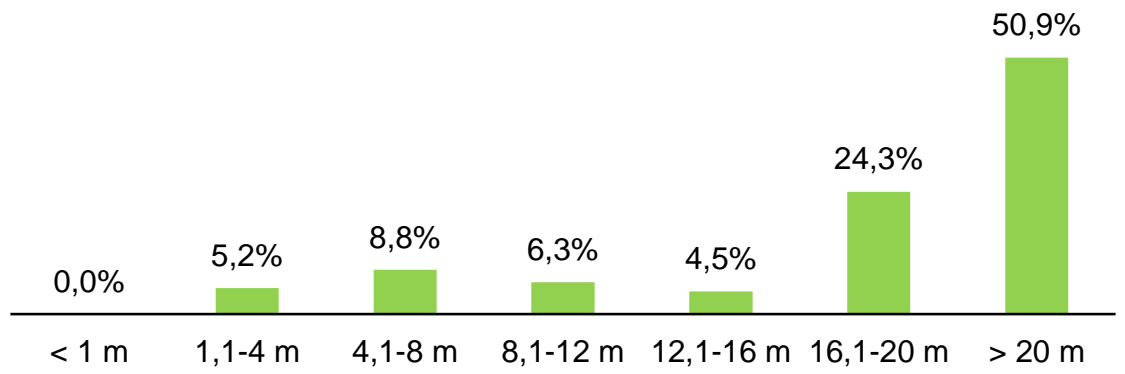

Figura 4. Características gerais das espécies presentes na Avenida Brasil, Bairro Centro em Passo Fundo, RS, 2019. Estado geral das plantas (a), altura média das espécies (b) e diâmetro médio de copa das espécies (c).

Figure 4. General characteristics of the species present on Brazil Avenue, Centro neighborhood in Passo Fundo, RS, 2019. General condition of the plants (a), average height of the species (b) and average diameter of the species (c). 


\section{CONCLUSÕES}

A Avenida Brasil do município de Passo Fundo no trecho correspondente a extensão de 2.516,75 m, apresenta alta diversidade de 427 espécies arbóreas, com bom índice de riqueza de espécies de 11,79. Desse número de espécies apenas $8,4 \%$ foi classificado estado em declínio, que podem causar danos ou queda desses indivíduos vegetais, sendo recomendado a sua susbtituição, além das espécies classificadas como inadequadas para a arborização urbana. Assim, sugere-se o plantio de espécies de origem, preferencialmente nativa, para essa substituição.

\section{REFERÊNCIAS}

ANDREATTA, T. R.; BACKES, F. A. A. L.; BELLÉ, R. A.; NEUHAUS, M.; GIRARDI, L. B.; SCHWAB, N. T.; BRANDÃO, B. S. Análise da arborização no contexto urbano de avenidas de Santa Maria, RS. Revista da Sociedade Brasileira de Arborização Urbana, Piracicaba, v.6, n.1, p.36-50, 2011.

BIONDI, D.; PEDROSA-MACEDO, J. H.. Plantas invasoras encontradas na área urbana de Curitiba (PR). Floresta, Curitiba, v. 38, n. 1, p. 129-144, 2008.

BRASIL. Constituição da República Federativa do Brasil: promulgada em 5 de outubro de 1988. Disponível em: <http://www.planalto.gov.br/ ccivil_03/constituicao/constituicao.htm>. Acesso em: 14 set. 2019.

CABRAL, P. I. D. Arborização Urbana: Problemas e Benefícios. Especialize On-line IPOG, Goiânia, v. 1, n. 6, p. 1-15, 2013.

DIAS, J.; COSTA, D. Sugestões de espécies arbóreas nativas ocorrentes no sul do estado do Paraná para fins ornamentais. União da Vitória: FAFIUV, 2008. 28 p.

FALCÃO, R. S.; GOMES, R.; PÉRES, M. Z.; OLIVEIRA, J. T.; CALLEGARO, R. M. Análise qualiquantitativa da arborização de cinco praças em Jerônimo Monteiro, Espírito Santo. REVSBAU, Curitiba, v.15, n.2, p. 90-103, 2020.

IBGE Cidades@ - INSTITUTO BRASILEIRO DE GEOGRAFIA E ESTATÍSTICA PARA AS CIDADES BRASILEIRAS. RS - Faxinal do Soturno. 2019. Disponível em: < https://cidades.ibge.gov.br/brasil/rs/faxinal-do-soturno/panorama>. Acesso em: 30 de novembro de 2019.

KENNEY, W. A.; VAN WASSENAER, P. J. E.; SATEL, A. L. Criteria and indicators for strategic urban forest planning and management. Arboriculture \& Urban Forestry, Atlanta, v. 17, n. 3, p. 108-117, 2011.

LORENZI, H. Plantas para jardim no Brasil: arbustivas, herbáceas e trepadeiras. 2.ed. Nova Odessa: Instituto Plantarum, 2015. 1120p. 
LORENZI, H; SOUZA, H. M. Plantas ornamentais no Brasil: arbustivas, herbáceas e trepadeiras. Nova Odessa: Instituto Plantarum, 2008. 1088p.

MARTINI, A; BIONDI, D. Microclima e Conforto Térmico de um Fragmento de Floresta Urbana em Curitiba, PR. Floresta e Ambiente, Rio de Janeiro, v. 22, n. 2, p. 182-193, 2015.

MELO, E. F. R. Q.; SEVERO, B. M. A. Avenida Brasil (Passo Fundo, Rio Grande do Sul): diversidade da vegetação e qualidade ambiental. Revista da Sociedade Brasileira de Arborização Urbana, Piracicaba, v.5, n.3, p.01-17, 2010.

MENEGAes, J. F.; MAGANO, D. A.; COStA, E. C.; TREVISSAN, P. V.; BARBIERI, M. Valoração ambiental sobre a perspectiva dos princípios da prevenção e da precaução. Ciência e Natura, Santa Maria, v. 36, n.2, p. 675-682, 2014.

NECKEL, A.; GRUB, J. PORTELLA, J.; BERNANDES, F. L. A elaboração de mapas mentais: estudo da influência da Avenida Brasil no desenvolvimento urbano da cidade de Passo Fundo/RS. Revista de Arquitetura da IMED, v. 3, n.1, p. 41-50, 2014.

PASSO FUNDO. Prefeitura Municipal - Infraestrutura. Disponível em: <http://www.pmpf.rs.gov.br/interna.php?t=19\&c=11\&i=13478>. Acesso em 18 mar.2020.

RESENDE, O. M. Arborização Urbana, 2011, 28f. Monografia (Geografia e Meio Ambiente), Universidade Presidente Antônio Carlos, Barbacena, 2011.

ROBBA, F.; MACEDO, S. S. Praças Brasileiras. São Paulo: EDUSP, 2010. 312 p.

SANTOS, A.; MORAES, R.; ISFER, A. C. A.; ALFACE, B. S. Manual de arborização urbana do município de São Paulo. São Paulo: Prefeitura de São Paulo, 2015. 124p.

SCHWAB, N. T.; GIRARDI, L. B.; NEUHAUS, M.; BACKES, F. A. A. L.; BELLÉ, R. A.; MENEGAES, J. F. Diversidade florística do bairro Nossa Senhora das Dores em Santa Maria, RS. Revista Brasileira de Horticultura Ornamental, Campinas, v. 20, n.2, p. 155-162, 2014.

SEBRAE - SERVIÇO DE APOIO ÀS MICRO E PEQUENAS EMPRESAS. SEBRAE Perfil Cidades Gaúchas - Faxinal do Soturno. 2019 Disponível em: <https://datasebrae.com.br/municipios/rs/Perfil_Cidades_Gauchas-Faxinal_do_Soturno.pdf>. Acesso em: 30 de novembro de 2019.

SILVA FILHO, D. F.; PIZETTA, P. U. C.; ALMEIDA, J. B. S. A.; PIVETTA, K. F. L.; FERRAUDO, A. S. Banco de dados relacional para cadastro, avaliação e manejo da arborização em vias públicas. Revista Árvore, Viçosa, v.26, n.5, p. 629-642, 2002.

SILVA, L. D. C.; CALEGARO, R. M.; SOARES, K. P.; CAPOS, J. R. A.; MENEGUELLI, F. Inventário e diagnóstico da arborização em quatro áreas públicas na cidade de Guaçuí - ES. Revista da Sociedade Brasileira de Arborização Urbana, Piracicaba, v. 12, n. 2, p. 117-128, 2017.

TEIXEIRA, I. F.; SILVA, R. M.; TATSCH, G. L. Compatibilidade da arborização de ruas da Avenida Celestino Cavalheiro, São Gabriel-RS. Floresta e Ambiente. Seropédica, v.18, n.4, p. 438-450, 2011.

VIEZZER, J.; BIONDI, D.; MARTINI, A.; GRISE, M. M. A vegetação no paisagismo das praças de Curitiba - PR. Ciência Florestal, Santa Maria, v. 28, n. 1, p. 369-383, 2018. 